Christer Svensén MD PhD,

Sari Ponzer MD PhD, Robert G. Hahn MD PhD

\title{
Volume kinetics of Ringer solution after surgery for hip fracture
}

Purpose: To study the time course of volume changes during and after infusion of Ringer's solution in elderly patients after a standardised trauma.

Methods: The kinetics of $12.5 \mathrm{ml} \cdot \mathrm{kg}^{-1}$ Ringer's solution infused over 30 min were studied in ten patients one day after surgery for hip fracture (mean age, $70 \mathrm{yr}$ ) and in an age- and sex-matched control group. Hemodilution, as measured every five minutes for $90 \mathrm{~min}$, was used to calculate the size of the fluid space expanded by the fluid $(V)$ and the elimination rate constant $\left(k_{r}\right)$. The baseline fluid balance status in the patients and the controls was compared by bioelectrical impedance analysis.

Results: The size of $V$ was $4.1 \pm 0.51$ (mean \pm SEM) in the patients and $3.4 \pm 0.21$ in the controls $(P$ :NS) while the corresponding results for $k_{r}$ were $85 \pm 12$ and $166 \pm 27 \mathrm{ml} \cdot \mathrm{min}^{-1}$, respectively $(P<0.04)$. Bioelectrical impedance analysis showed that the extracellular fluid space and the total body water volumes did not differ between the two groups. Computer simulations based on the data obtained for $V$ and $k_{r}$ indicate that trauma increases the dilution of the plasma volume and the retention of fluid in response to slow and moderate infusion rates, while these indices of short-term changes in fluid balance remain the same in the two groups during very rapid infusion of Ringer's solution.

Conclusion: A slower elimination rate increased dilution of plasma and retention of fluid when Ringer's solution was infused in elderly trauma patients.

Objectif: Examiner l'évolution des changements de volume pendant et après une perfusion de liquide de Ringer chez des patients âgés qui ont subi un trauma comparable.

Méthode : Un jour après une chirurgie de la hanche, la cinétique de $12,5 \mathrm{ml} \cdot \mathrm{kg}^{-1}$ de liquide de Ringer, perfusé pendant $30 \mathrm{~min}$, a été étudiée chez dix patients (âge moyen de 70 ans) et chez des patients témoins appariés selon l'âge et le sexe. L'hémodilution, par des mesures faites toutes les cinq minutes pendant 90 min, a servi au calcul du volume du compartiment liquidien, expansé par le fluide $(V$, et de la constante de vitesse d'élimination $\left(k_{\mathrm{e}}\right)$. Le bilan hydrique initial des patients a été comparé à celui des témoins par une analyse de l'impédance bioélectrique.

Résultats : La valeur de $V$ a été de 4,1 $\pm 0,5$ I (moyenne \pm l'erreur type) chez les patients et de 3,4 $\pm 0,21$ chez les témoins $(P: N S)$ et les résultats correspondants pour $k_{e}$ ont été de $85 \pm 12$ et de $166 \pm 27 \mathrm{ml} \cdot \mathrm{min}^{-1}$, respectivement $(P<0,04)$. Suivant l'analyse de l'impédance bioélectrique, le compartiment extracellulaire et le volume d'eau total de l'organisme n'affichaient pas de différence intergroupe. Des simulations sur ordinateur à partir des valeurs observées de $V$ et de $k_{\mathrm{e}}$ ont indiqué que le trauma augmente la dilution du volume plasmatique et la rétention de liquide lors d'une perfusion lente et modérée, mais que ces indices de changement de courte durée du bilan hydrique demeurent les mêmes dans les deux groupes pendant une perfusion très rapide de liquide de Ringer.

Conclusion : Une vitesse d'élimination plus lente augmente la dilution du plasma et la rétention de liquide lors d'une perfusion de liquide de Ringer chez des patients âgés victimes de trauma.

From the Departments of Anaesthesia and Orthopaedics, Söder Hospital, S-118 83 Stockholm, Sweden.

Address correspondence to: Robert G. Hahn MD PhD, Professor of Anaesthesia, Karolinska institute, Department of Anaesthesia, Söder Hospital, S-118 83 Stockholm, Sweden. Phone: 46-8-6161-2226; Telefax: 46-8-616-2234; E-mail: Robert.Hahn@anest.sos.sll.se Accepted for publication November 7, 1998 
$\mathrm{T}$ RAUMA triggers a series of pathophysiological effects, many of which cause major fluid shifts in the body. Hemorrhage is followed by autotransfusion and diffusion of fluid from the extracellular to the intracellular space ${ }^{1,2}$ and the associated hypovolemia promotes peripheral vasoconstriction and possibly local hypoxia and accumulation of acid. ${ }^{2}$ Microvascular perfusion is further impaired by hyperadhesive leucocytes that plug the capillaries ${ }^{3}$ and the increased cellular permeability leads to the release of intracellular enzymes and ions. ${ }^{4}$ Other effects are triggered by cytokines such as interleukin- 6 and interleukin-8. ${ }^{5}$ This complicated network of events makes it difficult to provide optimal fluid therapy based on clinical experience. The task is important, however, as adequate volume restoration may prevent the late sequelae of trauma. ${ }^{4}$

In the present study, we used a recently developed kinetic model to evaluate how trauma of moderate severity influenced the disposition of Ringer's solution. Fitting this model to an index of plasma dilution makes it possible to estimate the volume of the fluid space in the body that is expanded by the parenteral infusion of fluid $(V)$ and a constant governing the rate of elimination of the fluid $\left(k_{\mathrm{r}}\right)$. $^{6-8}$ The sampled plasma is then a part of $V$. The practical consequences of differences in volume kinetics between trauma patients and a control group can then be outlined by computer simulation in a way similar to the use of pharmacokinetic models to predict the outcome of any specified input in drug therapy. ${ }^{9}$ To obtain a standardised group of subjects with a trauma response, we studied patients who had just undergone open surgical repair of trochanteric fracture of the femur. Bioelectrical impedance analyses were performed to examine whether the patients and the controls had the same fluid balance status. ${ }^{10,11}$

\section{Methods}

Ten patients suffering from a trochanteric femur fracture aged between 51 and 94 yr (mean 76) were studied. Exclusion criteria were dementia, severe pulmonary and heart disease, and an elevated serum creatinine concentration. Eight patients were ASA I-II while 2 were ASA III. Four patients had been given a clinical diagnosis of mild congestive heart failure and were treated with once daily dose of diuretics, but had no symptoms. As a control group, we recruited ten volunteers, ASA I-II, aged between 53 and $77 \mathrm{yr}$ (mean 71), and not undergoing anesthesia and surgery. One subject had been given a clinical diagnosis of mild congestive heart failure and was treated with a daily dose of diuretics. The study was approved by the Ethics Committee and each subject gave his/her informed consent to participate.

\section{Procedure}

Patients who were admitted to hospital for trochanteric femur fracture were asked to participate. They were enrolled in the morning on the day of surgery, between 8 and $24 \mathrm{hr}$ after admission and when traction had already been applied. After fasting overnight and under spinal anesthesia, each patient was treated with internal fixation sometime between $10.00 \mathrm{a} . \mathrm{m}$. and 2.00 p.m. Intravenous (iv) fluid therapy was the traditional one used at this hospital, consisting of 500-1,000 ml Ringer's acetate solution (Pharmacia, Uppsala, Sweden) with an electrolyte content of $\mathrm{Na} 130, \mathrm{~K} 4, \mathrm{Ca} 2, \mathrm{Mg} \mathrm{l}$, acetate 30 and $\mathrm{Cl} 110 \mathrm{mmol} \cdot \mathrm{l}^{-1}$ preoperatively (depending on the time that elapsed before surgery), another $1,000 \mathrm{ml}$ during induction of spinal anesthesia, and $2,000 \mathrm{ml}$ of Ringer's-glucose solution (50\% glucose $50 \mathrm{~g} \cdot \mathrm{l}^{-1}$ and $50 \%$ Ringer's acetate) during and after surgery. Records were made of all ip fluids given. The patients were allowed to eat dinner after the operation, but they then fasted overnight until the experimental ip infusion of Ringer's acetate solution was performed, starting at 8.00 a.m. on the day after surgery. Cannulae were inserted into the antecubital vein of both arms for the purpose of infusion and blood sampling. After at least $20 \mathrm{~min}$ of equilibration in the recumbent position, Ringer's solution, $12.5 \mathrm{ml} \cdot \mathrm{kg}^{-1}$, was infused at a constant rate, over $30 \mathrm{~min}$, with the aid of an infusion pump (FloGard 6201, Baxter Healthcare Ltd., Deerfield, IL, USA).

Each patient with a fracture was matched with a healthy volunteer control of the same sex who underwent only experimental infusion of Ringer's solution. The controls were reasonably age-matched $( \pm 3 \mathrm{yr})$, except for the patient aged $94 \mathrm{yr}$ who was matched with a volunteer aged 77 .

\section{Measurements}

Samples $(3 \mathrm{ml})$ for measuring hemoglobin $(\mathrm{B}-\mathrm{Hb})$ concentration by a Technicon H.2 (Bayer, Tarrytown, N.Y., USA) were drawn from the venous cannula not used for infusion before experimental infusion of Ringer's solution, every five minutes during the infusion, and continuously every five minutes after the infusion for $90 \mathrm{~min}$. The first sample was drawn in duplicate and the mean value was used in the calculations. The coefficient of variation for the $\mathrm{B}-\mathrm{Hb}$ assay based on these duplicate samples was $0.7 \%$. After each sample had been obtained, the heart rate and arterial blood pressure were measured using an automatic device (Propaq 104, Protocol Systems Inc., Beaverton, Ore., USA) immediately after a blood sample had been obtained. 
TABLE I Demographic and volume kinetic data for an intravenous infusion of $12.5 \mathrm{ml} \cdot \mathrm{kg}^{-1}$ Ringer's solution over $30 \mathrm{~min}$ in 10 elderly patients who had undergone surgery for hip fracture and in 10 controls. Data are the mean and the variability (SEM) for the group.

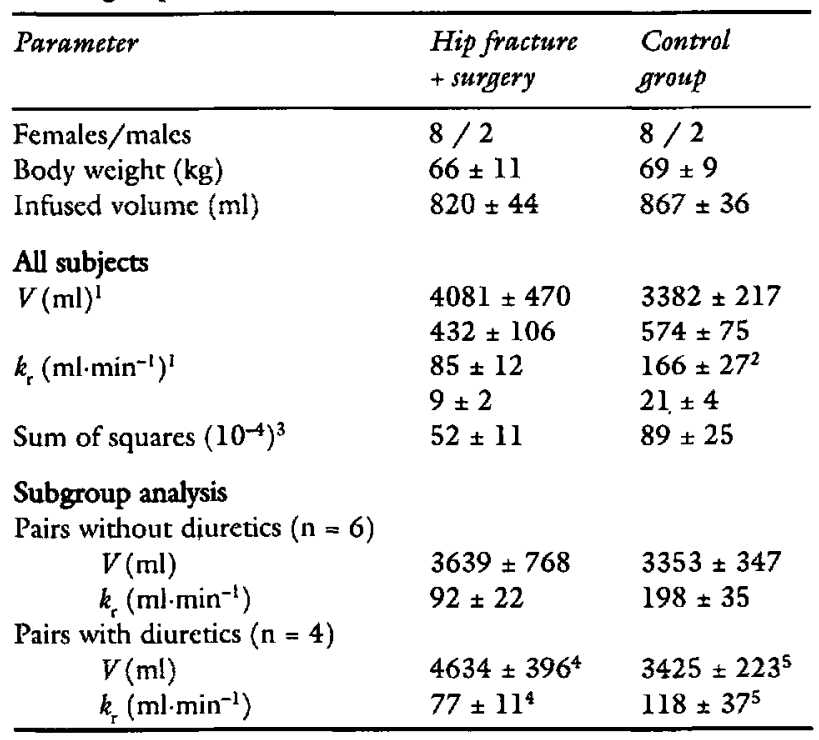

1 The first line gives the estimate and the second line its standard error.

${ }^{2}$ Difference between patients and controls significant by $P<0.04$.

${ }^{3}$ Sum of the squared differences between the model-generated and measured data points.

${ }^{4}$ All 4 had diuretic treatment, ${ }^{5}$ one had diuretic treatment.

Biochemical evidence of the severity of trauma, just before the experimental infusion, was obtained by measuring the plasma concentration of C-reactive protein using an immuno-turbidimetric assay (Tinaquant, Boehringer Systems, Mannheim, Germany) and the interleukin- 6 and interleukin- 8 levels by immunoassay (Quantikine, RD Systems, Minneapolis, $M N$, USA). The coefficient of variation for these analyses was $<4 \%, 4.3 \%$ and $6.5 \%$, respectively. The values could be lower depending on the concentration range measured.

Bioelectrical impedance analysis using a Xitron 4000B Spectrum Analyser (Xitron Tehnologies Inc., San Diego, CA, USA) for measuring total body water and extracellular water volumes was performed before surgery, after surgery, and just before and after the experimental infusion of Ringer's solution. The bioelectrical analysis involved sending small currents in a series of 50 frequencies between $5 \mathrm{kHz}$ to $500 \mathrm{kHz}$ through the patient via four electrodes placed on the right foot and right arm. The coefficient of variation for serial measurements were $0.3 \%$ for the extracellular fluid volume and $2.0 \%$ for total body water.
TABLE II Bioimpedance analysis at the time of the operation and at the experimental infusion of Ringer's solution. Each parameter represents the mean of six measurements, half of which were taken before and after the operation and experimental infusion, respectively.

\begin{tabular}{lll}
\hline & Hip fracture & Control grout \\
\hline Operation (Day 1) & & \\
Extracellular fluid volume (1) & $14.3 \pm 0.8^{*}$ & \\
\% of body weight & $22.5 \pm 0.6^{*}$ & \\
Total body water (1) & $24.8 \pm 1.5^{*}$ & \\
\% of body weight & $39.1 \pm 1.3^{*}$ & \\
Experiment (Day 2) & & \\
Extracellular fluid volume (1) & $15.8 \pm 1.0$ & $16.0 \pm 0.9$ \\
$\quad$ \% of body weight & $24.1 \pm 0.6$ & $23.1 \pm 0.4$ \\
Total body water (1) & $27.5 \pm 1.5$ & $28.3 \pm 1.5$ \\
$\quad$ \% of body weight & $42.0 \pm 1.2$ & $40.8 \pm 0.6$ \\
\hline
\end{tabular}

* Significantly different at $P<0.01$ from the value obtained during the experiment. The extracellular fluid volume increased by $100 \mathrm{ml}$ (mean) during the infusion experiment. Values are means (SEM). No differences between patients and controls were significant.

TABLE III Fluid balance data noted during the period between admittance to hospital and the experimental infusion of Ringer's solution.

\begin{tabular}{lll} 
Parameter & Mean & SEM \\
\hline$I v$ fluid before surgery $(\mathrm{ml})$ & 600 & 221 \\
Operating time (min) & 58 & 12 \\
$I v$ fluid during/after surgery $(\mathrm{ml})$ & 2300 & 475 \\
${\text { Erythrocyte transfusion }(\mathrm{ml})^{1}}_{\text {Surgical blood loss }(\mathrm{ml})}$ & 260 & 101 \\
Postoperative blood loss $(\mathrm{ml})^{2}$ & 220 & 62 \\
\hline
\end{tabular}

Volumes were zero except in ${ }^{1}$ five patients and in ${ }^{2}$ threc patients.

\section{Calculations}

The distribution of the fluid infused $i v$ was modeled separately for each subject using a kinetic model ${ }^{6-8}$ based on the assumption that the volume of the fluid space expanded by the infused fluid strives to be maintained in a way similar to an elastic balloon. A fluid given by $i v$ infusion at a rate $k_{i}$ is distributed in an expandable space with a volume (v) which the fluid space strives to maintain at a baseline (target) volume (V). Fluid leaves the space at a basal rate, representing perspiration from the expanded body fluid space and baseline diuresis $\left(k_{\mathrm{b}}\right)$ and at a controlled rate proportional by a constant $\left(k_{\mathrm{r}}\right)$ to the deviation from the target volume. The following equation describes the situation for the single-volume fluid space model:

$$
\mathrm{d} v=k_{\mathrm{i}}-k_{\mathrm{b}}-k_{\mathrm{r}} \frac{(v-V)}{V}
$$


During (d) and after (a) infusion, the solution to this differential equation is

$$
\begin{array}{ll}
w_{d}(t)=\frac{\left(k_{\mathrm{i}}-k_{\mathrm{b}}\right)\left(1-\mathrm{e}^{-k \mathrm{r} t / N}\right)}{k_{\mathrm{r}}} & 0 \leq t \leq t_{1} \\
w_{a}(t)=\left(w_{d(t 1)+\frac{k_{\mathrm{b}}}{k_{\mathrm{r}}} \mathrm{e}^{-k \tau(\mathrm{r}-\mathrm{r} 1) / \mathrm{N}}-\frac{k_{\mathrm{b}}}{k_{\mathrm{r}}}}\right. & t_{1} \leq t \leq \infty
\end{array}
$$

where $t_{1}$ is the infusion duration and $\mathrm{w}(t)$ is the dilution of the sampled space, $(v(t)-V) / V$, at time $t$. The dilution of the plasma in the cubital vein was used to quantitate the water load since Ringer's solution remains outside the erythrocytes. As the sampled plasma is a part of $V$, we obtain:

$$
\frac{(v(t)-V)}{V}=\frac{[\text { baseline B-Hb/B-Hb }(t)]-1}{(1-\text { baseline hematocit })}
$$

$\mathrm{A} \mathrm{k}_{\mathrm{b}}$ of $0.8 \mathrm{ml} \cdot \mathrm{min}^{-1}\left(1,150 \mathrm{ml} \cdot 24 \mathrm{hr}^{-1}\right)$ has previously been employed in healthy volunteers who had fasted overnight ${ }^{8}$ and corresponds to an insensible fluid loss of $10 \mathrm{ml} \cdot 24 \mathrm{hr}^{-1} 12$ with an addition for fluid loss with the blood sampling of $0.3 \mathrm{ml} \cdot \mathrm{min}^{-1}$. These baseline net fluid losses are likely to be reduced in the presence of trauma, however, due to inhibition of spontaneous diuresis and also to a shift of fluid from the cells to the extracellular space due to increased blood glucose levels. ${ }^{4}$ To take this compensation into account, $k_{b}$ was set to $0.4 \mathrm{ml} \cdot \mathrm{min}^{-1}$ in the hip fracture patients while $0.8 \mathrm{ml} \cdot \mathrm{min}^{-1}$ was still used in the controls. A correction for the losses of erythrocytes and extracellular fluid associated with the blood sampling was also made as described previously. ${ }^{8}$

Estimates of the unknown parameters were obtained by using non-linear least-squares regression based on a modified Gauss-Newton method. The iterations stopped when all parameters had changed less than $0.1 \%$ in two iterations. The curve-fitting was performed using Matlab 4.2 (Math Works Inc., Notich, Mass., USA) and the output consisted of data for $V$ and $k_{\mathrm{r}}$ together with their standard errors, the latter expressing the precision by which the parameter values were estimated.

The results are given as the mean and the standard error of the mean (SEM) for the respective group of subjects. Statistical evaluation was carried out using one-way and repeated-measures analysis of variance (ANOVA). $P<0.05$ was considered significant.

\section{Results}

Dilution of the plasma was more variable during the infusion of Ringer's solution in the patients with trochanteric fractures than in the control group (Figure 1).
The volume kinetic analysis showed that the elimination rate constant $\left(k_{\mathrm{r}}\right)$ was half as large in the patient group as in the volunteers $(P<0.04)$. A slightly larger body fluid space was expanded by the infused fluid $(V)$ in the patients (4.1 l) than in the controls (3.4 l), but this difference was not statistically significant (Table I, middle). The diuretic-treated patients contributed to most of the difference in $V$ but relatively little to the difference in $k_{\mathrm{r}}$ between the patients and the controls (Table I, bottom).

As the size of $V$ did not differ markedly between the patients and the controls, the dilution-time and the volume-time curves based on the mean parameter values had a similar appearance (Figure 2). The reported differences in volume kinetic constants are highlighted in further computer-generated simulations of the expected dilution-time profiles resulting from of various fluid regimens (Figure 3 ).

The subjects differed in hemodynamic and biochemical profiles in such a way as to indicate the presence of moderately severe trauma response in the patient group. The diastolic arterial pressure was lower $(P<0.001)$ and the heart rate was higher $(P<0.001)$ in the patients (Figure 4 ) and they also had elevated plasma levels of markers of systemic inflammatory activity (Figure 5).

Bioimpedance analysis showed similar values for the extracellular and total body water volumes when the infusions were performed (Table II). However, the patients had lower body fluid volumes $(P<0.01)$ when the operation was performed than on the day of the infusion experiment (Table II). The restoration of body fluid volumes between the surgery and the experiment can be understood from the fluid balance data. They indicate that the patients received modest volume replacement up to the time of surgery, while they were better hydrated between the operation and the infusion experiment (Table III).

\section{Discussion}

This study compared the volume effect of $i v$ infusion of Ringer's solution after trauma in elderly patients with that measured in a reasonably matched control group. In both the surgical patients and in the controls, dilution of the plasma fraction of the blood was measured during and after infusion of a standard amount of fluid. A kinetic model was fitted to the data in which the infused fluid was assumed to occupy a single fluid space in the body which has a baseline volume $V$. The elimination of fluid when $V$ is expanded to size $v$ is governed primarily by the elimination rate constant $\left(k_{\mathrm{r}}\right)$, which correlates well with the urinary excretion when multiplied by the dilution of the expanded body fluid space, 


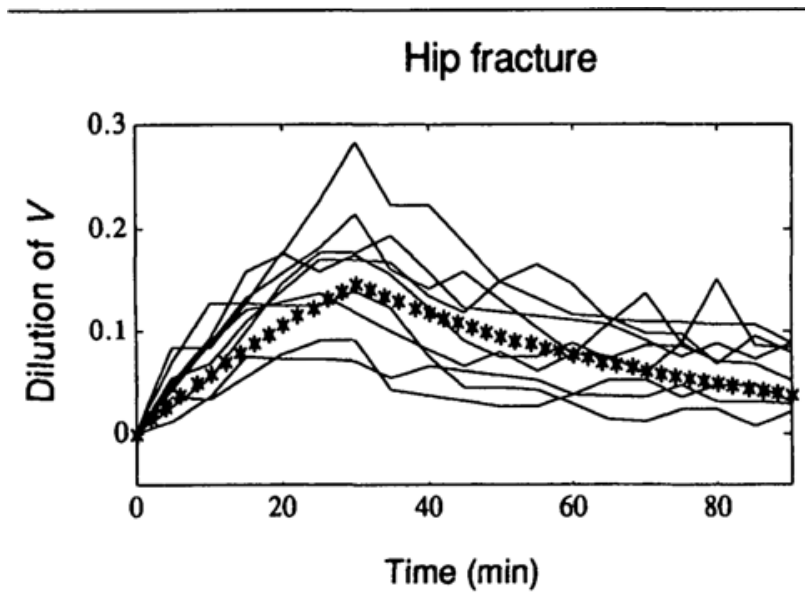

Controls

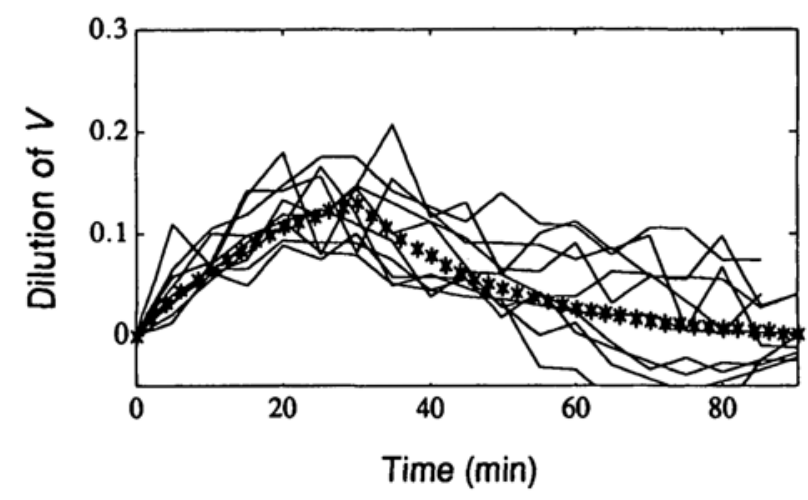

FIGURE I Individual dilution-time curves (fine lines) during and after infusion of Ringer solution in patients who had undergone surgical repair of a hip fracture (top graph) and in healthy controls (bottom graph). The heavy line in each graph is the model-predicted curve based on mean values of the parameters in the one-volume kinetic model. All data were corrected for blood sampling.

$(\mathfrak{p}-V) / V^{7}$ By using these symbols, it becomes apparent that the excess volume in the body is given by $(p-V)$.

The results indicate that the trauma we studied, consisting of hip fracture followed by traction and internal fixation, had no effect on the size of $V$. The average $V$ was $20 \%$ larger than in the controls, but this difference was not consistent. The elimination rate constant was, however, much lower in the patients than in the controls $\left(85\right.$ vs $166 \mathrm{ml} \cdot \mathrm{min}^{-1}$ ). This suggests that $k_{\mathrm{r}}$ is an important factor governing the difference in plasma dilution between trauma patients and normal subjects receiving Ringer's solution.

The practical consequences of the body's altered handling of infused fluid after trauma in elderly people became evident in our computer-based simulations.
These are examples of how the differences in volume kinetic parameters between the patients and the controls are likely to alter the dilution of $V$ during and after Ringer's solution is infused in various volumes and rates. The simulations suggest that the dilution is the same as in control subjects during but not after rapid infusion of the fluid. Furthermore, the dilution is more pronounced in association with low infusion rates in trauma patients. For infusions lasting two three hours, the low $k_{\mathrm{r}}$ associated with trauma would allow the rate of infusion to be reduced by $40 \%$ and still result in the same dilution as in the controls.

The present kinetic results were obtained by using the one-volume fluid-space model, although a two-volume space model has also been developed..$^{7,8}$ However, there was a strong within patient covariance (correlation matrix -0.99) between $k_{\mathrm{r}}$ and the size of the peripheral fluid space in two out of the three analyses in each group in which the two-volume model resulted in a significant reduction of the mean square error associated with the curve fitting. ${ }^{8}$ Such a high degree of correlation implies that these two parameters behaved as one parameter. We have later understood that the intercorrelation problem can probably be avoided by sampling blood for a longer time after the infusion. Furthermore, the two-volume model can be stabilized by calculating $\mathrm{k}_{\mathrm{r}}$ directly from the urinary excretion, ${ }^{13}$ but this possibility was not known when the present study started. As urine volumes were not systematically measured, the results obtained with the two-volume model were not considered to be sufficiently meaningful to warrant publication.

The infusion experiments were performed with the assumption that the patients and the controls were comparable in all respects except the exposure to trauma. A "stress" response is indicated by the hemodynamic measurements, where the higher heart rate and the lower diastolic blood pressure is consistent with adrenaline stimulation. The biochemical markers of inflammatory activity also showed clear evidence of a trauma response. The serum concentration of interleukin-6 increases after major surgery and reaches a peak after $12 \mathrm{hr} .{ }^{14} \mathrm{C}$-reactive protein, which is a part of the acute phase response to cytokine stimulation, peaks after two days. For both markers, higher levels can be measured after greater surgical trauma. ${ }^{14}$ Interleukin-8 is a potent chemotactic agent for neutrophils, which become elevated in response to ischemic/reperfusion injury, and possibly also after other forms of tissue damage. ${ }^{5}$ In the present study, the serum concentrations of C-reactive protein and interleukin- 6 were about 100 times higher and the interleukin-8 levels were three times higher in the patients than in the controls. We 

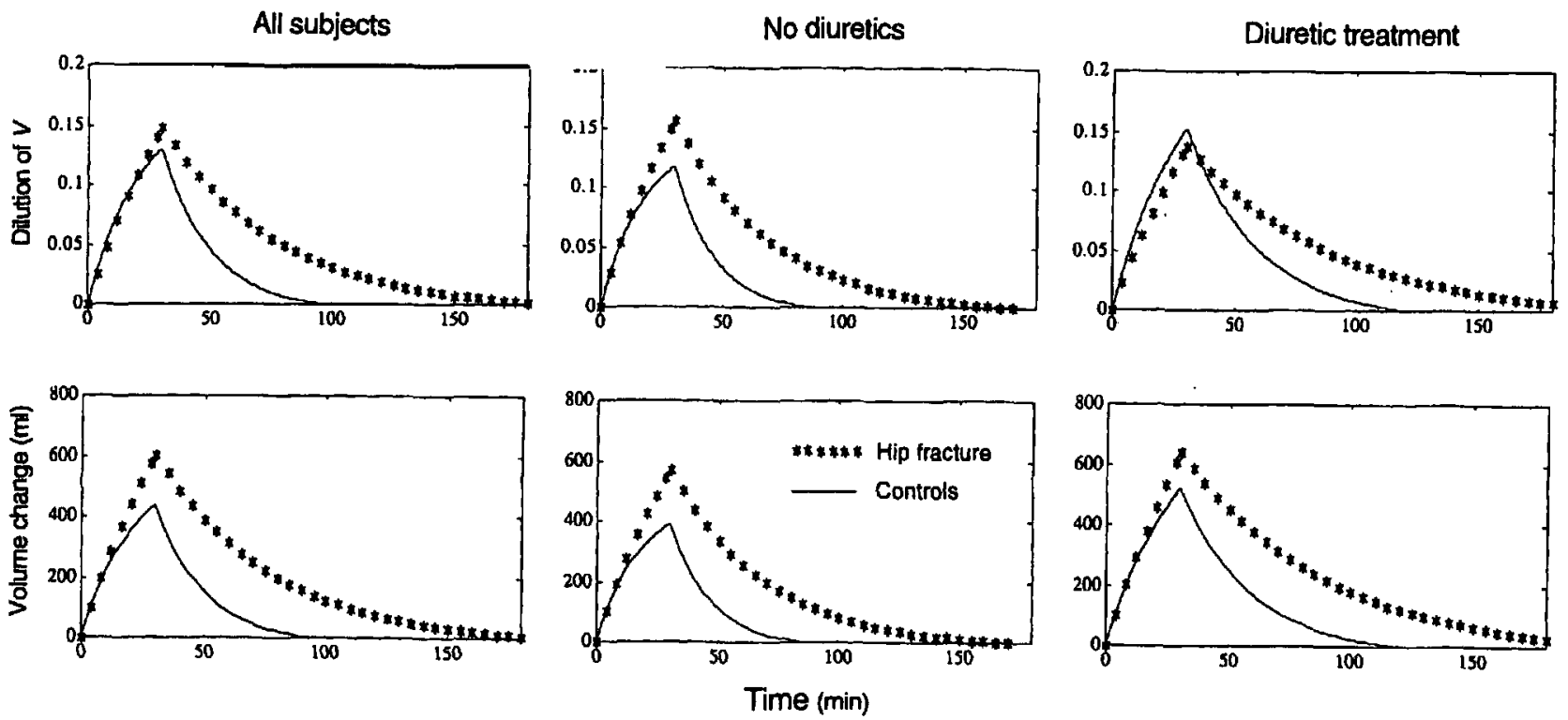

FIGURE 2 The dilution-time profiles (upper row) and the volume-time profiles (lower row) based on the mean parameter values resulting from iv infusion of $12.5 \mathrm{ml} \cdot \mathrm{kg}^{-1}$ of Ringer's solution over $30 \mathrm{~min}$ in all subjects (left), in the six patients and controls where diuretic treatment was not given (middle), and the four pairs of subjects where diuretic treatment was involved (right). The curves are prolonged to show the predicted time required for the dilution of $V$ to return to zero and for the excess volume to become eliminated. The graphs in the lower row were obtained by multiplying the dilution, $(p-V) / V$, by the size of the expanded body fluid space, $V$, to obtain the volume change, $(p-V)$.

reduced the value given to $k_{b}$ in the volume kinetic analysis from 0.8 to $0.4 \mathrm{ml} \cdot \mathrm{min}^{-1}$ in the trauma patients to account for vasopressin-induced reduction of the spontaneous diuresis, although this modification has very limited effect on the model parameters when such a large amount of fluid as $12.5 \mathrm{ml} \cdot \mathrm{kg}^{-1}$ is infused over a short time.

Many patients admitted for surgery were excluded because of concurrent disease. The reported patient group therefore represents a healthier part of the population undergoing surgery for trochanteric hip fracture. The parients and the controls were matched with respect to age and sex, but it was still difficult to control for all mild forms of medical disease. It is very common for old people in Sweden to be treated with a daily dose of diuretic for mild congestive heart disease. The diagnosis is usually clinical and uncertain. A subanalysis showed that the patients receiving diuretic treatment accounted for most of the $20 \%$ difference in $V$ between the patients and the controls. Although the limited sample sizes prevent meaningful statistical comparisons between the groups with respect to diuretic treatment from being made, $k_{\mathrm{r}}$ was practically the same in the trauma patients who were treated with a diuretic (77 $\left.\mathrm{ml} \cdot \mathrm{min}^{-1}\right)$ as in the other trauma patients $\left(92 \mathrm{ml} \cdot \mathrm{min}^{-1}\right)$.
Figure 2 confirms that the dilution of $V$ and the retention of fluid in the body was more pronounced after trauma in both the diuretic-treated and the diuretic-free subjects. This suggests that, regardless of diuretic treatment, a prolonged time-course of the dilution of $V$ which is explained by a low $k_{r}$ can be regarded as a sequel of trauma.

The fluid balance at the time of the infusion experiment was also of concern. The experiment was performed on the day after surgery because we believed that acute fluid shifts associated with the operation would have then probably been restored. An adequate comparison of the volume kinetics between trauma patients and healthy controls would require that the anatomical fluid volumes are similar. The bioelectrical analysis of body fluid volumes carried out on the first postoperative day showed no difference between the groups. The simple and painless bioimpedance analysis technique is considered accurate for studies of body fluid volumes in groups of subjects. ${ }^{11}$ Therefore, we believe that the average anatomical body fluid volumes in our groups of subjects were of the same size.

The bioelectrical measurements carried out before and just after the operation support our assumption that the day of surgery would be a less good choice for 

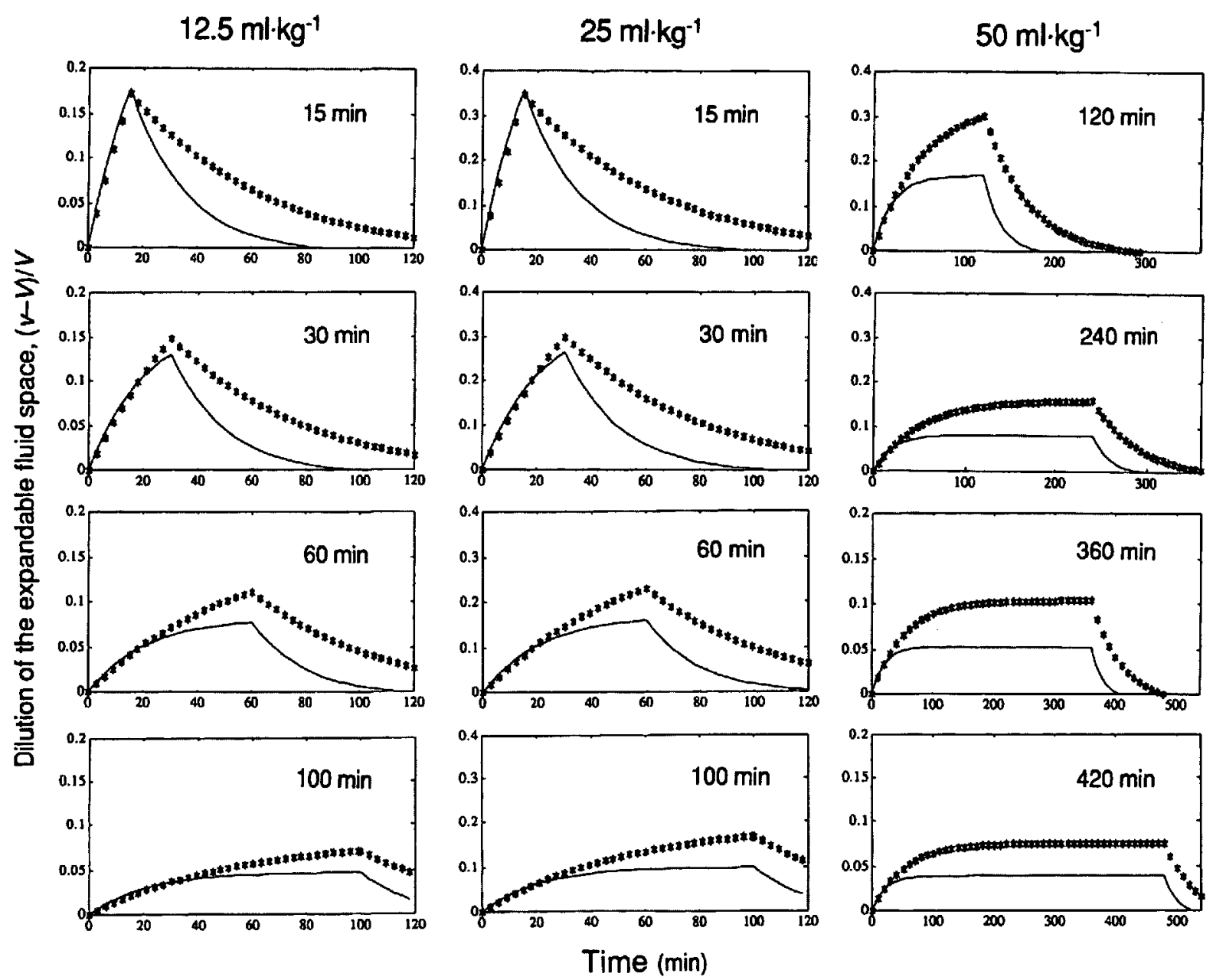

FIGURE 3 Computer-generated curves representing the dilution of the plasma volume over time when Ringer solution is infused in various volumes (given on top of each column) and over various periods of time (specified inside each graph) in trauma pacients (dotted lines) and controls (fine lines).

the infusion experiment. The extracellular fluid volume was $1,500 \mathrm{ml}$ smaller and the total body water $2,500 \mathrm{ml}$ smaller on the day of surgery than on the first postoperative day. The reason for the reduced body fluid volumes is probably a combination of modest preoperative fluid administration and sequestration of fluid into the area of the fracture which, similar to urine, gastric contents and blood, ${ }^{15}$ is unlikely to be measured by bioimpedance. About $3,000 \mathrm{ml}$ of crystalloid fluid, instead of the average $600 \mathrm{ml}$ that was actually given, would be required from admission to hospital until the operation to maintain the sizes of the anatomical body fluid spaces. As we believe this is good practice during trauma and surgery, our bioimpedance measurements performed at the time of the operation have resulted in a change in practice at our hospital towards a more liberal fluid regimen in patients awaiting surgery for hip fracture.

The dilution of $V$ can be used to estimate several other parameters that are clinically useful. As the sampled plasma is a part of $V$, dilution of $V$ is equivalent to dilution of plasma. A plasma volume curve can then be obtained by multiplying the dilution-time function $(\nu(t)-V) / V)$ by an assumed or measured baseline plasma volume. The dilution of $V$ also represents a corresponding dilution of the total intravascular space, which is smaller but can be obtained by multiplying the data by ( 1 -baseline hematocrit).

An interesting feature is that a dilution-time plot $(v(t)-V) / V)$ can be converted into a volume-time plot 

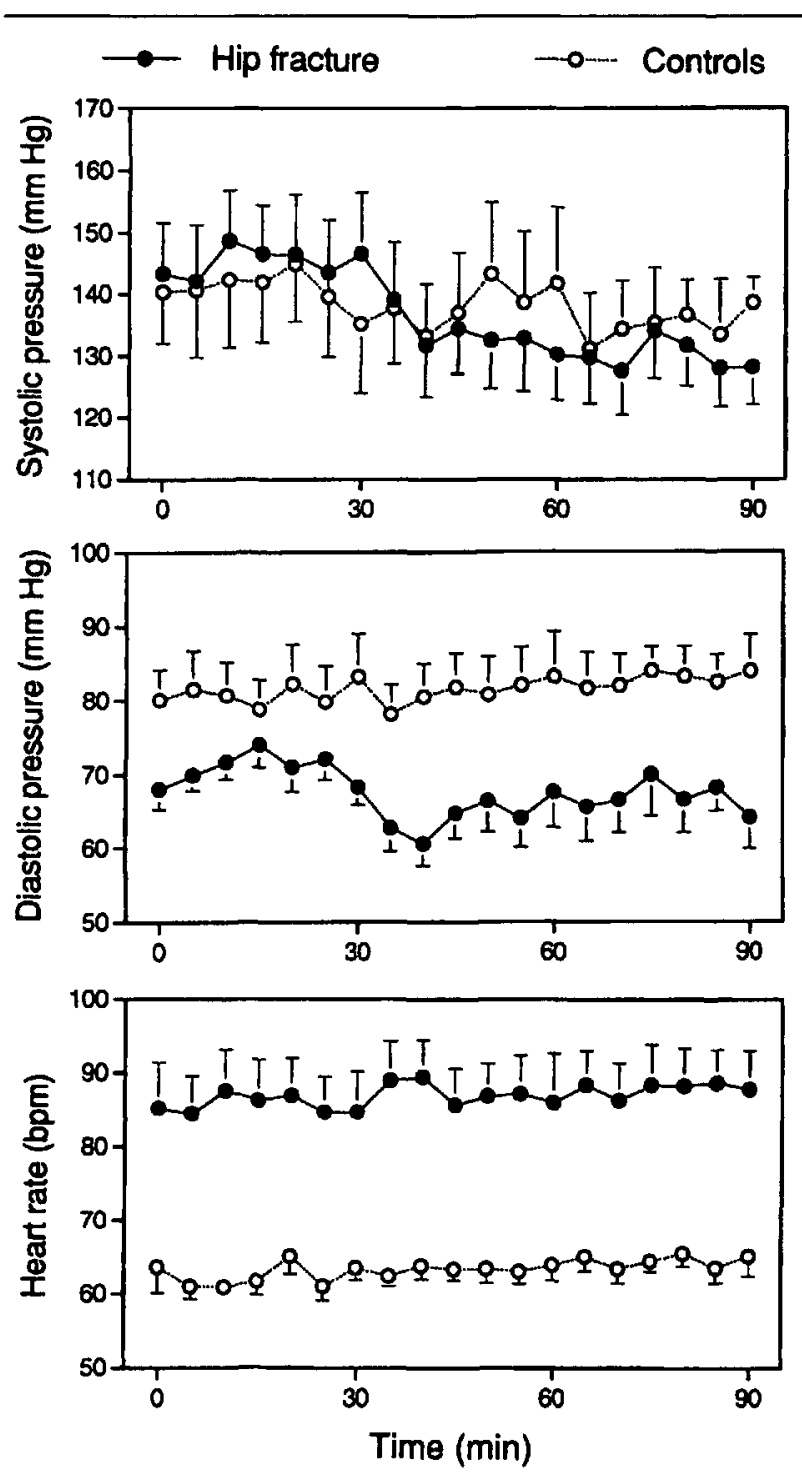

FIGURE 4 Hemodynamic parameters obtained during the infusion experiments with Ringer's solution in patients with trochanteric fracture (filled circles) and in a control group (open circles).

by multiplying the function by $V$ to obtain $(p(t)-V)$. Then, however, we no longer consider the volume of the intravascular space but the entire body fluid space that is expanded by the infused fluid. In the present study, the similarity in the size of $V$ between the patients and the controls even allows us to extend the simulations of dilution changes to volume changes without intermediate calculations. More exactly the volume $(p-V)$ can be obtained (in litres) for any time during the various fluid regimens simulated in Figure 3 by multiplying the plotted dilution by 4.1 (patients) and 3.4 (controls). The volume-time plots show a slightly larger difference

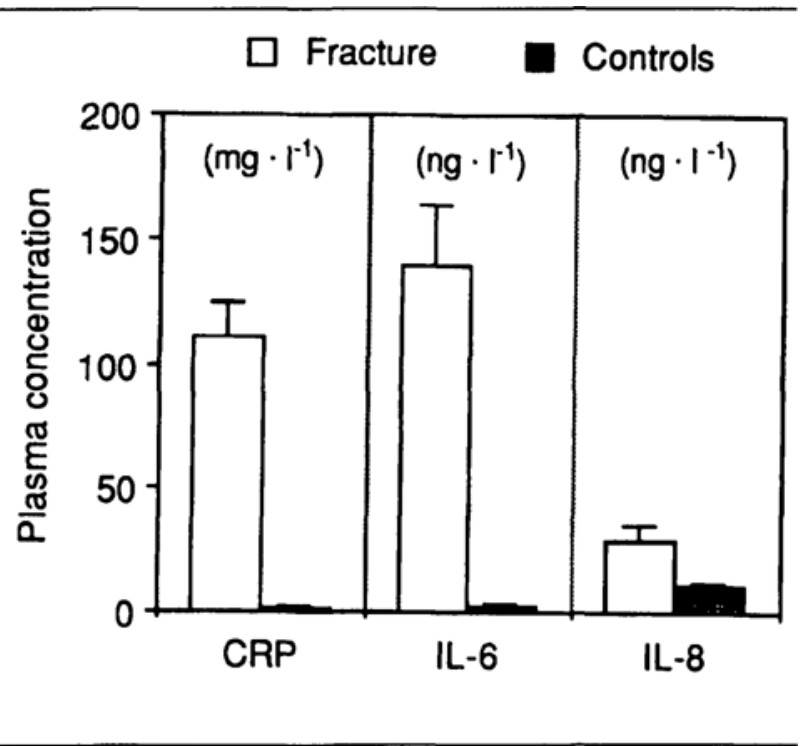

FIGURE 5 Plasma concentrations of C-reactive protein, interleukin- 6 and interleukin- 8 just before the infusion experiments with Ringer's solution started in patients with a hip fracture (open bars) and in a control group (dark bars). For all parameters, the plasma concentration was higher after trauma $(P<0.01)$.

between the two groups, but all qualitative relationships shown in the dilution-time plots are maintained.

It is important to note that a volume-time plot obtained in this way does not represent the increase of plasma volume, as $V$ is usually larger than the expected plasma volume. It, rather, yields the sum of the expansion of the plasma volume and probably of perivascular areas of the interstitial fluid space which become expanded by the infused fluid. The change in intravascular volume is better indicated by the dilution-time curve than by the volume-time curve; the blood volume (BV) at time $t$ is given by the function $B V(t)=[1+(v(t)-V) / V)]$ * baseline $B V$.

In conclusion, slower elimination of fluid increases the volume effect of Ringer's solution infused in elderly trauma patients.

\section{Acknowledgment}

Eva Thuresson assisted during the experiments.

\section{References}

1 Lister J, McNeill IF, Marshall VC, Plzak LF, Dagher FJ, Moore FD. Transcapillary refilling after hemorrhage in normal man: basal rates and volumes; effect of norepinephrinc. Ann Surg 1963; 158: 698-712.

2 Riddez L, Habn RG, Brismar B, Strandberg $A$, Svensén $C$, Hedenstierna $G$. Central and regional hemodynamics during acute hypovolemia and volume substitution in volunteers. Crit Care Med 1997; 25: 635-40. 
3 Braide $M$, Amundson $B$, Chien $S$, Bagge $U$. Quantitative studies on the influence of leukocytes on vascular resistance in a skeletal muscle preparation. Microvasc Res 1984; 27: 331-52.

4 Haljamäe H. Pathophysiology of shock-induced disturbances in tissue homeostasis. Acta Anaesthesiol Scand 1985; 29: 38-44.

5 Sheeran P, Hall GM. Cytokines in anaesthesia. Br J Anaesth 1997; 78: 201-19.

6 Staible $L$, Nilsson A, Habn RG. Modelling the volume of expandable body fluid spaces during i.v. fluid therapy. Br J Anaesth 1997; 78: 138-43.

7 Hahn R G, Drobin D, Ståble L. Volume kinetics of Ringer's solution in female volunteers. $\mathrm{Br} J$ Anaesth 1997; 78: 144-8.

8 Svensén C, Hahn RG. Volume kinetics of Ringer solution, dextran 70, and hypertonic saline in male volunteers. Anesthesiology 1997; 87: 204-12.

9 Habn RG, Svensén C. Plasma dilution and the rate of infusion of Ringer's solution. Br J Anaesth 1997; 79 : 64-7.

10 Johnson HL, Virk SPS, Mayclin P, Barbieri T. Predicting total body water and extracellular fluid volumes from bioelectrical measurements of the human body. J Am Coll Nutr 1992; 11: 539-47.

11 Dal Cin S, Braga M, Molinari M, Cristallo $M$, di Carlo $V$. Role of bioelectrical impedance analysis in acutely dehydrated subjects. Clin Nutr 1992; 11: 128-33.

12 Cox $P$. Insensible water loss and its assessment in adult patients: a review. Acta Anaesthesiol Scand 1987; 31 : 771-6.

$13 H a b n R G$. Drobin D. Urinary excretion as an input variable in volume kinetic analysis of Ringer's acetate. Br J Anaesth 1998; 80: 183-8.

14 Cruickshank AM, Fraser WD, Burns HJG, van Damme $J$, Shenkin $A$. Response of serum interleukin- 6 in patients undergoing elective surgery of varying severity. Clin Sci 1990; 79: 161-5.

15 Tedner $B$. In pipo fluid-volume monitoring with impedance technique. Thesis, Karolinska Institutet, Stockholm, Sweden 1985: 47-53. 